\title{
PEDAGOGY
}

\section{ABOUT THE PRACTICE OF ACTIVE LEARNING METHODS}

\author{
L. Silchenko', T. Zubova ${ }^{2}$ \\ DOI: http://doi.org/10.15350/L_26/10/2
}

\section{Abstract}

It's reported about the practice of using active learning methods in teaching the disciplines of the natural science and economic cycles for extramural studies.

Keywords: professional competences, active methods, individual homeworks, point-rating system of knowledge control.

Компетентностный подход в образовании требует увеличения доли активных методов обучения, которые нацелены на усилении роли самостоятельной работы обучающихся под руководством преподавателя не в роли передатчика информации, а в роли менеджера учебного процесса [1, с.3; 2, с.46].

Контингент обучающихся по заочной форме обучения характеризуется как разнообразием возрастного, так и начального образовательного ценза.

Работа с разнородной аудиторией требует детализации индивидуального подхода, но усвоение основ изучаемого материала одинаково необходимо как тем, кто захочет совершенствоваться далее, углубляя свои познания, в частности, в магистратуре, так и для тех обучаемых, кто лишь соприкоснется с изучаемыми дисциплинами за время своего обучения. С этой точки зрения важно обеспечить саму систему содержания курса преподаваемых дисциплин таким образом, чтобы в их основе лежало постепенное развитие понятий, терминов, законов, теорий в единую систему знаний.

\footnotetext{
${ }^{1}$ Lidiia Silchenko, Candidate of Chemical Sciences, Associate Professor, Bryansk Regional Cossack Institute of Technology and Management (branch) of the federal state budgetary educational institution of higher education "Moscow State University of Technology and Management K.G. Razumovsky (First Cossack University), Russia.

${ }^{2}$ Tatiyana Zubova, Associate Professor, Bryansk Regional Cossack Institute of Technology and Management (branch) of the federal state budgetary educational institution of higher education "Moscow State University of Technology and Management K.G. Razumovsky (First Cossack University), Russia.
} 
Следствием системности содержания является системность знаний обучающихся при организации оптимальных форм учебного процесса. Системность знаний - основа развития рациональных приемов учебной работы, умение экономически мыслить и переносить знания на решение новых познавательных задач. Системность знаний - это путь к самостоятельности, самообразованию, развитию творческих способностей, в общем, это ключ к умению учиться.

Именно умение учиться - необходимое, если не самое главное условие получения соответствующего образования по заочной форме обучения, где самостоятельная работа составляет основную долю учебного процесса.

Для естественных наук это достигается посредством обобщения тематического материала на основе поиска связей (генетических, причинноследственных, взаимного влияния) между изучаемыми объектами. Систематизация и обобщение материала может осуществляться на примере химических дисциплин путем решения как расчетных, так и экспериментальных задач по различным разделам химии. При этом на разном теоретическом материале отрабатываются алгоритмы решения задач, что способствует отлаженному механизму усвоения как теоретических, так и практических (экспериментальных) знаний.

В экономическом обучении также важно ориентироваться не только на формирование системы знаний, обеспечивающих соответствующий уровень компетентности, но и на освоение навыков и умений, необходимых для практической деятельности. В комплексе это стимулирует самостоятельное развитие профессиональных компетенций и умение их применять в новых ситуациях.

Поскольку экономисты так же, как и будущие специалисты-технологи, связаны с постоянным решением производственных вопросов, важное значение в обучении приобретают задачи активизации обучения, чему в полной мере соответствует такой вид учебного процесса, как задания ситуационного характера, связанные с анализом конкретных технологических или экономических ситуаций. Такие задания формируют техникоэкономический стиль будущего специалиста, его умение ориентироваться в нестандартных ситуациях.

Моделирование профессиональных умений будущего специалиста реализуется через ряд взаимосвязанных этапов, включающих

- ознакомление в ходе бесед, дискуссий и других форм общения с обучающимися с основами профессиональной деятельности;

- формирование ценностных профессиональных ориентаций в ходе учебных экскурсий, участия в конкурсах, олимпиадах, мастер-классах;

- реализация учебных проектов, участие в научно-исследовательской деятельности, написание научных статей.

Средства развивающего обучения позволяют выявить разноуровневую подготовку обучающихся уже на первоначальном этапе обучения, а также их индивидуальные способности и осуществить дифференциацию на этапах обучения и контроля, т.е. в процессе самостоятельной работы. 
При осуществлении дифференцированного подхода хорошо зарекомендовал себя прием выдачи индивидуальных домашних заданий (ИДЗ), в том числе и заданий с «нарастающей трудностью», когда для ответов на одни вопросы требуются только репродуктивные знания, для ответов на другие не обойтись без сравнений, для ответов на третьи уже необходим анализ с раскрытием причинно-следственных связей, а четвертая и другие группы вопросов требуют уже переноса знаний, их творческое переосмысливание и применение, серьезной интеллектуальной подготовки, привлечение дополнительного литературного материала, владение информационными технологиями, математическими методами обработки и моделирования.

Выдача такого типа индивидуальных заданий в качестве домашних позволяет глубже и шире отразить их обучающий и контролирующий характер в рамках балльно-рейтинговой системы, практикуемой в ряде вузов.

С другой стороны, это стимулирует самостоятельную подготовку обучающихся в межсессионный период, нацеливая обучающихся на реализацию такой формы промежуточной аттестации, как экзамен (зачет) - «автомат».

В отличие от традиционных формализованных форм обучения и контроля знаний, например, тестирования, активные формы обучения позволяют осуществить аутентичную оценку, дающую студенту не одну возможность успешно завершить задание. В качестве такой формы выступает такой способ аутентичной оценки как портфолио [2, с.44].

Реализация «портфолио» как активной технологии обучения предполагает пошаговое документальное отслеживание продуктов образовательного процесса обучаемого не в сравнении с другими обучающимися, а в сравнении с самим собой за отдельные промежутки времени. При этом связь с преподавателем является обязательным условием на всех этапах данной технологии.

Ведение портфолио позволяет обучающимся сформулировать конкретные цели обучения и задачи для достижения поставленных целей, а преподавателю дает реальный материал для оценки самостоятельной работы обучающихся. ИДЗ, о которых сообщалось выше, могут рассматриваться как обязательный элемент портфолио, задаваемый преподавателем.

Организация активных форм обучения невозможна без серьезной подготовки как обучающегося, так и преподавателя, под руководством которого осуществляется учебный процесс, поэтому создание условий для двустороннего мотивирования является залогом успешного образовательного процесса. 
References:

[1] Газизова Г. М., «Использование методов интерактивного обучения как фактор успешного овладения студентами профессиональными компетенциями» //Труды МЭЛИ: электронный журнал. - 2008 - №7 - C 8. (http://www.meli.ru/emagazine/vipusk7.htm).

[2] На пути в Единое европейское пространство высшего образования: Учебное пособие / Под ред. А.О. Грудзинского. - Нижний Новгород: ННГУ им. Н.И. Лобачевского, 2011. - 163с. 